\title{
Clinical Reasoning: Ketogenic diet in adult super- refractory status epilepticus
}

Ika Noviawaty, MD, Eliza Olaru, MD, Caitlin Rondello, RD, Brian Fitzsimmons, MD, and

Manoj Raghavan, MD, PhD

Neurology ${ }^{\circledR} 2020 ; 94: 541-546$. doi:10.1212/WNL.0000000000009137

\author{
Correspondence \\ Dr. Noviawaty \\ ikanoviawaty@gmail.com.
}

\section{Section 1}

We present a case of super-refractory status epilepticus (SRSE) in a previously healthy 38-yearold right-handed man who initially presented at an outside hospital after a car accident. He was the driver, and had a witnessed convulsive event at the scene. A week previously, he had presented to the outside hospital with fever $\left(102^{\circ} \mathrm{F}\right)$, flu-like symptoms, and low back pain, and was discharged home on hydrocodone/acetaminophen. Upon presentation after the car accident, the patient was febrile and displayed fluctuating mental status without meningeal signs. There were no focal deficits on neurologic examination. Preliminary diagnostic studies included lumbar puncture (LP), which showed an elevated opening pressure of $35 \mathrm{~cm} \mathrm{H}_{2} \mathrm{O}$, and pleocytosis, with 42 leukocytes/mL (54\% lymphocytes). MRI of the brain with and without contrast showed hyperintense fluid-attenuated inversion recovery (FLAIR) signal and restricted diffusion in the left hippocampus. There were no imaging findings to support traumatic brain injury. Acyclovir treatment was started. An IV loading dosage of phenytoin was administered immediately after his presentation in the outside hospital. Serial EEGs thereafter showed evidence of electrographic seizures arising from the right frontotemporal region, which continued despite IV loads of phenobarbital and levetiracetam. It was unclear if benzodiazepine was tried initially. The patient was transferred to our hospital for management of refractory status epilepticus (RSE). Continuous EEG monitoring upon transfer was consistent with partial status epilepticus with seizures originating from the right frontotemporal region (figure).

\section{Questions for consideration:}

1. What other questions are pertinent to establishing the etiology of the status epilepticus in this patient?

2. Where would you localize the pathology? 
Figure EEG findings

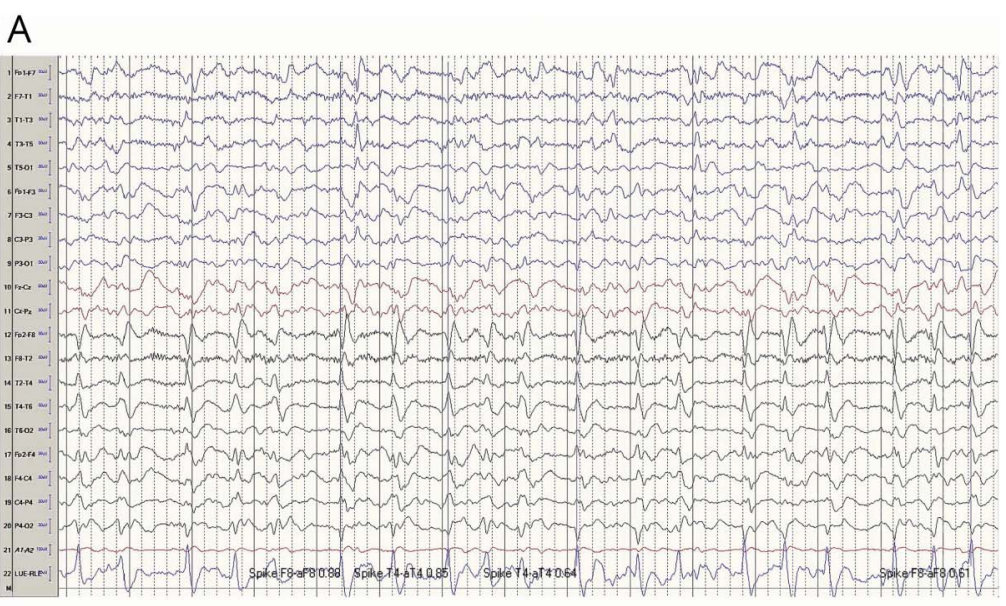

B

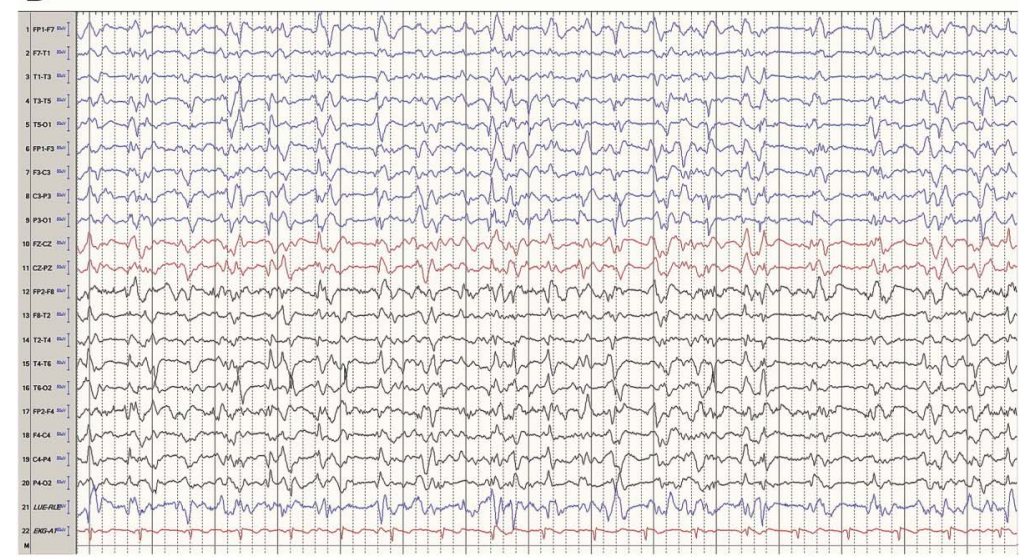

C

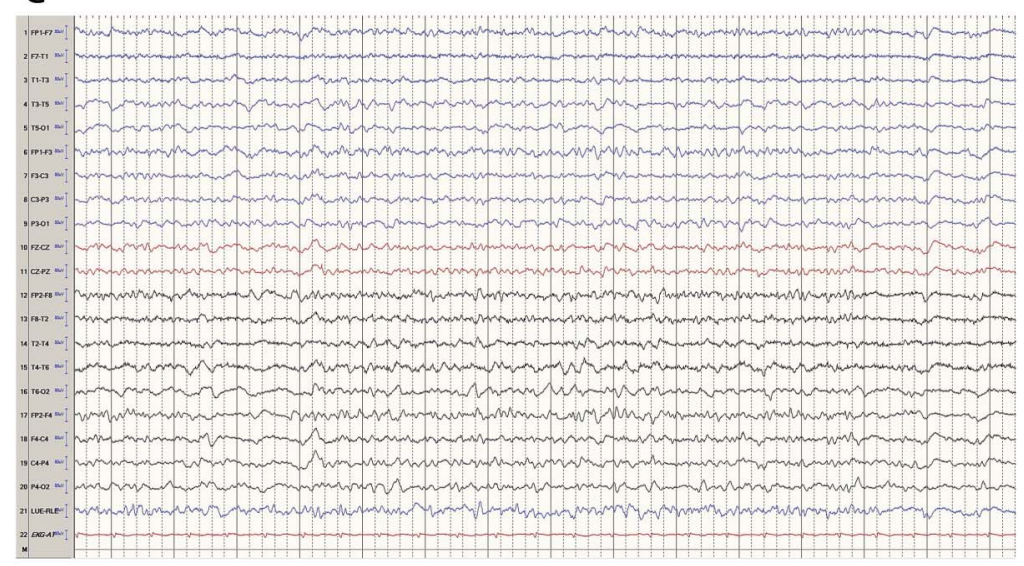

(A) EEG on the day of transfer to our hospital. (B) EEG on the day ketogenic diet was started. (C) EEG 1 day after ketosis was achieved.

\section{GO TO SECTION 2}




\section{Section 2}

Further history revealed no recent sick contact, ingestion of raw food, or travel. The patient had no history of febrile seizures in childhood, head trauma, malignancy, autoimmune disorder, or epilepsy. There was no family history of epilepsy or autoimmune disorder. The patient is the product of a normal pregnancy, labor, and delivery, and his developmental history was unremarkable. He worked as a carpenter and enjoyed hunting.
The EEG seizures contralateral to MRI changes are likely due to deep epileptic onset with spread to the contralateral side. This spread was captured by scalp EEG. The altered mental status, fever, and pleocytosis is concerning for status epilepticus secondary to more systemic etiology.

\section{Questions for consideration:}

1. What differential diagnosis would you consider?

2. What additional diagnostic tests should be ordered?

GO TO SECTION 3 


\section{Section 3}

The differential diagnosis included infections such as herpes encephalitis, autoimmune disorders such as NMDA encephalitis, metabolic disorders, and paraneoplastic processes and pleocytosis secondary to seizures. No clear etiology can be found in $10 \%$ of status epilepticus cases. ${ }^{2}$ Therefore, workup for infectious etiologies should be pursued along with metabolic and autoimmune workup for all cases of new-onset RSE (NORSE) of unknown etiology. ${ }^{1-3}$ In our patient, the elevated opening pressure and pleocytosis noted on the initial LP and CSF studies had normalized on the follow-up CSF studies. Other CSF studies performed in our hospital included glucose, protein, Gram stain and culture, cytology, rapid plasma reagin, Lyme disease screening, Herpes Simplex virus, Varicella-Zoster virus, Cytomegalovirus, Epstein-Barr virus, Cryptococcus, West Nile virus, and Eastern and Western Equine viruses. These studies as well as blood cultures were negative. Serum HIV, Bartonella cat scratch disease, thyroid-stimulating hormone, NMDA antibodies, and paraneoplastic processes are also part of the important differential diagnosis for NORSE. In our case, extensive screening for viral agents, antibodies related to paraneoplastic processes (antiNMDA, VGKC, anti-Ma, anti-Ta, anti-Hu, CASPR2, CV2, CRMP5, amphiphysin, GAD65, LGI1 antibodies), thyroid function, and thyroid antibodies also returned negative results. Plasma acylcarnitine profile was ordered to screen for disorders of fatty acid oxidation and organic acid metabolism. Results showed mild elevations of C6, C8, C10, C6-dicarboxylic acid, and C8-dicarboxylic acid species with a nonspecific pattern. Carnitine level was normal. CT chest, abdomen, and pelvis and abdominal ultrasound were negative. No brain biopsy was performed. Follow-up 3T MRI brain with epilepsy protocol showed hyperintense FLAIR signal and restricted diffusion in both hippocampi. No other structural abnormalities were evident.

\section{Question for considerations:}

1. What treatments should be considered? 


\section{Section 4}

We continued the acyclovir that was started in the outside hospital for probable diagnosis of viral encephalitis. Phenytoin, levetiracetam, and phenobarbital were also continued. Upon transfer to our hospital, pentobarbital infusion was started to address the RSE, and EEG burst suppression was achieved. However, by day 7, the EEG showed a recurrence of focal seizures involving the temporal regions without clear lateralization of onsets. Anticonvulsant doses were advanced and lacosamide was added to the regimen. Midazolam infusion was added to the anticonvulsant regimen. Despite a multidrug anticonvulsant regimen and maximizing pentobarbital and midazolam, EEG continued to show seizures involving both temporal regions was well as stimulus-induced rhythmic, periodic, or ictal discharges (SIRPID) arising from a burst suppression pattern. Phenytoin was discontinued by day 18 due to a rash, elevated transaminases, and eosinophilia, which was suggestive of drug rash with eosinophilia and systemic symptoms. A course of prednisone was started with a slow taper over 2 weeks. An IV load of valproic acid was tried on day 38 , but maintenance doses were discontinued after 2 days due to lack of EEG response. Ketamine was tried thereafter, also without benefit. Clonazepam was added on day 44 while attempting to reduce midazolam infusion rates. After discussion of limited therapeutic options for NORSE with the family, the ketogenic diet (KD) was started 7 weeks after admission to hospital (Nutren 2.0, then switched to KetoCal 4:1 through gastrostomy tube) (figure). Daily urine acetoacetate and serum hydroxybutyrate was monitored and ketosis was achieved 5 days later. No other medication changes were made upon the initiation of KD. SIRPID and electrographic seizures decreased dramatically 2 days after achieving ketosis (figure). Eight days after achieving ketosis, weaning of pentobarbital was started. The EEG showed periods with sleep elements and better-organized background. Electrographic seizures reappeared while weaning pentobarbital; thus oxcarbazepine was added. The patient started to follow commands 16 days after ketosis. Due to appearance of sporadic seizures, pregabalin was added as pentobarbital taper was completed. The patient was transferred to the general floor on day 85. Oxcarbazepine was reduced due to appearance of hyponatremia around this time, and rufinamide was added. A vagus nerve stimulator (VNS)

Table 1 Treatment course

\begin{tabular}{|c|c|c|c|}
\hline Medication/treatment & $\begin{array}{l}\text { Timeline } \\
\text { initiated }\end{array}$ & Duration, d & Posttreatment EEG findings \\
\hline Acyclovir & Transfer day -7 & 14 & Multiple EEG seizures \\
\hline Phenytoin & Transfer day -7 & 25 & Multiple EEG seizures \\
\hline Levetiracetam & Transfer day -6 & $\begin{array}{l}\text { Continued until } \\
\text { discharge }\end{array}$ & Multiple EEG seizures \\
\hline Phenobarbital & Transfer day -5 & 25 & Multiple EEG seizures \\
\hline Pentobarbital & Day 1 & 56 & Status epilepticus $\rightarrow$ burst suppression $\rightarrow$ recurrent EEG seizures after 7 days \\
\hline Lacosamide & Day 7 & $\begin{array}{l}\text { Continued until } \\
\text { discharge }\end{array}$ & SIRPID, status epilepticus \\
\hline Midazolam IV & Day 7 & 37 & SIRPID, status epilepticus \\
\hline Steroid & Day 18 & 14 & SIRPID, status epilepticus \\
\hline Valproic acid & Day 38 & 2 & SIRPID, status epilepticus \\
\hline Ketamine & Day 40 & 4 & SIRPID, status epilepticus \\
\hline Clonazepam & Day 44 & $\begin{array}{l}\text { Continued until } \\
\text { discharge }\end{array}$ & SIRPID, status epilepticus \\
\hline Ketogenic diet & Day 49 & 68 & $\begin{array}{l}\text { EEG seizures dramatically decreased } 7 \text { days after initiation ( } 2 \text { days after ketosis } \\
\text { achieved) }\end{array}$ \\
\hline $\begin{array}{l}\text { Oxcarbazepine, } \\
\text { pregabalin }\end{array}$ & Day 59 & $\begin{array}{l}\text { Continued until } \\
\text { discharge }\end{array}$ & Controlled EEG seizures recurrence during pentobarbital weaning \\
\hline Rufinamide & Day 85 & $\begin{array}{l}\text { Continued until } \\
\text { discharge }\end{array}$ & Controlled the increased clinical seizures during oxcarbazepine dose reduction \\
\hline $\begin{array}{l}\text { Vagal nerve } \\
\text { stimulation }\end{array}$ & Day 109 & $\begin{array}{l}\text { Continued until } \\
\text { discharge }\end{array}$ & Aborting the complex partial seizures with magnet swipe \\
\hline Modified Atkins diet & Day 117 & $1 \mathrm{y}$ & Maintaining stable seizure frequency \\
\hline
\end{tabular}

Abbreviation: SIRPID = stimulus-induced rhythmic, periodic, or ictal discharges. 
Table 2 Vagus nerve stimulator settings

\begin{tabular}{lll}
\hline Current, mA & Initial & Discharge \\
\hline Pulse width, ms & 0.25 & 0.75 \\
\hline Frequency, Hz & 500 & 500 \\
\hline On time, s & 30 & 20 \\
\hline Off time, min & 30 & 7 \\
\hline Magnet activated current, mA & 5 & 0.3 \\
\hline Magnet activated pulse width, ms & 500 & 0.75 \\
\hline Magnet activated duration, s & 60 & 500 \\
\hline
\end{tabular}

was placed on day 109 due to further sporadic partial seizures, which were clinically characterized by left gaze deviation along with head turned to the left side followed by left facial twitching. The patient also manifested symptoms consistent with postictal psychosis, and was placed on risperidone. He was transitioned to a modified Atkins diet ( $<45 \mathrm{~g}$ of net carbohydrate) on day 117 for better tolerability. He was transferred to the rehabilitation service on day 135 and was discharged home after a 10-day stay with moderate to severe residual cognitive difficulties and a critical illness myopathy. Anticonvulsant regimen at discharge was lacosamide, levetiracetam, clonazepam, pregabalin, oxcarbazepine, and rufinamide in addition to VNS therapy (table 1). Rufinamide was eventually replaced with clobazam with gradual reduction of clonazepam. Follow-up MRI upon discharge showed decreased signal abnormalities in bilateral hippocampi. Currently, the patient lives at home, but requires supervision and is under the care of a local neurologist. The patient was transitioned to a regular diet within a period of 1 year and experienced no increase in seizure frequency. He continues to experience between 15 and 20 dyscognitive partial seizures every month despite good compliance with his anticonvulsant regimen and VNS therapy (table 2).

\section{Discussion}

RSE is commonly defined as status epilepticus resistant to 1 first-line anticonvulsant and 1 second-line anticonvulsant medication. Approximately $31 \%$ to $43 \%$ of patients with status epilepticus develop RSE, with mortality rate ranging from $16 \%$ to $22 \%{ }^{1-3}$ RSE carries a high risk of morbidity and mortality even with optimal medical management. When status epilepticus fails to respond to initial anesthetic therapy for $>24$ hours or if status epilepticus recurs during reduction of anesthetic agents, it has been referred to as SRSE. ${ }^{1}$ One of the alternative treatment options for SRSE based on several case reports is the $\mathrm{KD}^{4,9,10}$
$\mathrm{KD}$ is a high-fat, low-carbohydrate, and low-protein diet, which has been used in children with medically refractory epilepsy since the 1920s. The diet is tailored to provide $4: 1$ or 3:1 ratio of fat to the combined weight of carbohydrate and protein. The mechanism of the anticonvulsant effect of the $\mathrm{KD}$ is not well-understood. ${ }^{5}$ The $\mathrm{KD}$ may provide antiseizure effect by increasing neuronal inhibition. This may occur through a variety of mechanisms including alteration of GABA levels, GABA metabolism, or GABA receptors. ${ }^{6,7}$ High level of ketone bodies may also decrease glutamate concentration in the synaptic cleft, which can reduce neuronal excitation. ${ }^{8}$ In adults with medically refractory epilepsy, the traditional $\mathrm{KD}$ is usually not tolerable as a long-term treatment. In these cases, a modified Atkins diet (1:1 ratio) is a less restrictive option., ${ }^{9,10}$

Despite its proven anticonvulsant effect, the traditional $\mathrm{KD}$ has largely been used only in children, and typically not as a long-term treatment. There is growing experience for its use in adult status epilepticus reported in the literature. ${ }^{4}$ In our patient, the resolution of status epilepticus coincided with achieving ketosis and very likely represents a positive treatment response. The response observed in our patient along with other case reports in the literature support the use of KD in SRSE when traditional anticonvulsant therapies have failed.

\section{Author contributions}

I. Noviawaty: drafting, organizing, and editing the manuscript. E. Olaru: drafting part of the manuscript. C. Rondello: drafting part of the manuscript. B.-F. Fitzsimmons: drafting part of the manuscript. M. Raghavan: final revision.

\section{Study funding}

No targeted funding reported.

\section{Disclosure}

The authors report no disclosures relevant to the manuscript. Go to Neurology.org/N for full disclosures.

\section{References}

1. Shorvon S. Super refractory status epilepticus: an approach to therapy in this difficult situation. Epilepsia 2011;52(suppl 8):53-56.

2. Costello DJ, Kilbride RD, Cole AJ. Cryptogenic new onset refractory status epilepticus (NORSE) in adults: infectious or not? J Neurol Sci 2009;277:26-31.

3. Wilder-Smith EP, Lim EC, Teoh HL, et al. The NORSE (new-onset refractory status epilepticus) syndrome: defining a disease entity. Ann Acad Med Singapore 2005;34:417-420.

4. Kossoff EH, Nabbout R. Use of dietary therapy for status epilepticus. J Child Neurol 2013;28:1049-1051.

5. Hartman AL, Strafstrom CE. Harnessing the power of metabolism for seizure prevention: focus on dietary treatments. Epilepsy Behav 2013;26:266-272.

6. Lutas A, Yellen G. The ketogenic diet: metabolic influences on brain excitability and epilepsy. Trends Neurosci 2013;36:32-40.

7. Erecinska M, Nelson D, Daikhin Y, Yudkoff M. Regulation of GABA level in rat brain synaptosomes: fluxes through enzymes of the GABA shunt and effects of glutamate, calcium, and ketone bodies. J Neurochem 1996;67:2325-2334.

8. Juge N, Gray JA, Omote H, et al. Metabolic control of vesicular glutamate transport and release. Neuron 2010;68:99-112.

9. Thakur KT, Probasco JC, Hocker SE, et al. Ketogenic diet for adults in super refractory status epilepticus. Neurology 2014;82:665-670.

10. Nabbout R, Mazzuca M, Hubert P, et al. Efficacy of ketogenic diet in severe refractory status epilepticus initiating fever induced refractory epileptic encephalopathy in school age children (FIRES). Epilepsia 2010;51:2033-2037. 


\section{Neurology}

\section{Clinical Reasoning: Ketogenic diet in adult super-refractory status epilepticus}

Ika Noviawaty, Eliza Olaru, Caitlin Rondello, et al.

Neurology 2020;94;541-546 Published Online before print February 27, 2020

DOI 10.1212/WNL.0000000000009137

This information is current as of February 27, 2020

\begin{tabular}{|c|c|}
\hline $\begin{array}{l}\text { Updated Information \& } \\
\text { Services }\end{array}$ & $\begin{array}{l}\text { including high resolution figures, can be found at: } \\
\text { http://n.neurology.org/content/94/12/541.full }\end{array}$ \\
\hline References & $\begin{array}{l}\text { This article cites } 10 \text { articles, } 1 \text { of which you can access for free at: } \\
\text { http://n.neurology.org/content/94/12/541.full\#ref-list- } 1\end{array}$ \\
\hline Subspecialty Collections & $\begin{array}{l}\text { This article, along with others on similar topics, appears in the } \\
\text { following collection(s): } \\
\text { Antiepileptic drugs } \\
\text { http://n.neurology.org/cgi/collection/antiepileptic_drugs } \\
\text { Critical care } \\
\text { http://n.neurology.org/cgi/collection/critical_care } \\
\text { Status epilepticus } \\
\text { http://n.neurology.org/cgi/collection/status_epilepticus }\end{array}$ \\
\hline Permissions \& Licensing & $\begin{array}{l}\text { Information about reproducing this article in parts (figures,tables) or in } \\
\text { its entirety can be found online at: } \\
\text { http://www.neurology.org/about/about_the_journal\#permissions }\end{array}$ \\
\hline Reprints & $\begin{array}{l}\text { Information about ordering reprints can be found online: } \\
\text { http://n.neurology.org/subscribers/advertise }\end{array}$ \\
\hline
\end{tabular}

Neurology ${ }^{\circledR}$ is the official journal of the American Academy of Neurology. Published continuously since 1951, it is now a weekly with 48 issues per year. Copyright @ 2020 American Academy of Neurology. All rights reserved. Print ISSN: 0028-3878. Online ISSN: 1526-632X.

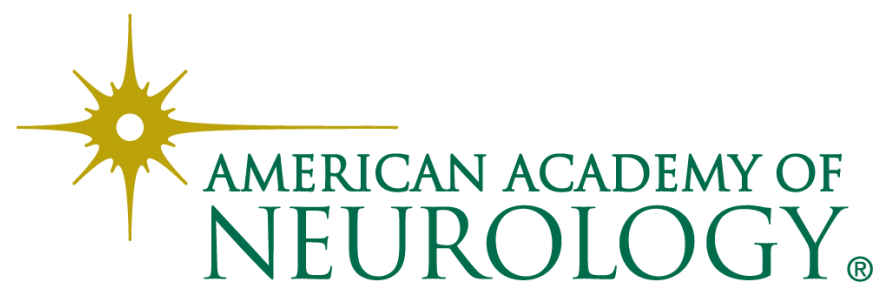

